\title{
Ilex paraguariensis Pellets from a Spray-Dried Extract: Development, Characterization, and Stability
}

\author{
Francini K. J. Yatsu, ${ }^{1}$ Greice S. Borghetti, ${ }^{1}$ Fagner Magalhães, ${ }^{2}$ Humberto G. Ferraz, ${ }^{2}$ \\ Eloir Paulo Schenkel, ${ }^{3}$ and Valquiria L. Bassani ${ }^{1,4}$
}

Received 27 March 2015; accepted 26 June 2015; published online 11 July 2015

\begin{abstract}
Several studies have shown the potential use of Ilex paraguariensis in developing products with the aim to protect biological systems against oxidative stress-mediated damages. In the same way, technological studies have demonstrated the feasibility of obtaining dry products, by spray-drying process, from aqueous extracts of I. paraguariensis in laboratory. The present work was designed to develop pellets by extrusion/spheronization process, from an I. paraguariensis spray-dried powder. The pellets were characterized with respect to their chemical, physical, and technological properties, and the thermal and the photostability of the main polyphenol constituents were investigated. The pellets exhibited adequate size, shape, and high process yield $(78.7 \%)$, as well as a good recovery of the total polyphenols ( $>95 \%)$ and a good dissolution in water (89.44 to $100.05 \%)$. The polyphenols were stable against light when conditioned in amber glass bottles; unstable against heat when the samples were conditioned either in open glass bottles or in hermetically sealed glass bottles and demonstrated to be hygroscopic and sensible to the temperature, especially when stored in permeable flasks. These findings pointed to the relevance of reducing the residual moisture content of pellets as well as of conditioning them in opaque humidity tight packages under low temperatures. The feasibility of obtaining pellets from an I. paraguariensis spray-dried powder using extrusion/spheronization technique was, for the first time, demonstrated. This finding represents a novelty for the herbal products in both pharmaceutical and food fields.
\end{abstract}

KEY WORDS: extrusion/spheronization; Ilex paraguariensis; pellets; spray-dried powder.

\section{INTRODUCTION}

Ilex paraguariensis is widely consumed in South America and it is gaining rapid introduction into the world market, either as a nonalcoholic beverage (tea and infusion) or as an ingredient of foods and dietary supplements. It has been shown that $I$. paraguariensis has a high antioxidant activity (1-4). It is hypocholesterolemic $(5,6)$, hepatoprotective (7), diuretic (8), and beneficial to the cardiovascular system (5). It is also able to protect DNA $(9,10)$ and low-density lipoproteins from oxidation (11).

\footnotetext{
${ }^{1}$ Programa de Pós-Graduação em Ciências Farmacêuticas, Universidade Federal do Rio Grande do Sul, Av. Ipiranga 2752, CEP 90610-000, Porto Alegre, RS, Brazil.

${ }^{2}$ Programa de Pós-Graduação em Ciências Farmacêuticas, Universidade de São Paulo, Av. Prof. Lineu Prestes 580, CEP 05508-000, São Paulo, SP, Brazil.

${ }^{3}$ Programa de Pós-Graduação em Ciências Farmacêuticas, Universidade Federal de Santa Catarina, Campus Universitário, Trindade, CEP 88040-970, Florianópolis, SC, Brazil.

${ }^{4}$ To whom correspondence should be addressed. (e-mail: valquiria.bassani@ufrgs.br)
}

In the same way, several studies have shown the potential use of I. paraguariensis in developing products with the aim to protect biological systems against oxidative stressmediated damages (12-14). Technological studies have demonstrated, for example, the feasibility of obtaining dry products, by spray-drying process, from aqueous extracts of I. paraguariensis in laboratory (15-17).

The processing of plant extractive solutions in dry extracts leads to products with higher concentration and stability and more homogeneous distribution of chemical constituents, as well as with easier transport and storage. However, dry extracts in general exhibit technological limitations, such as fine particles presenting low density and poor flow, which impair the direct production of pharmaceutical dosage forms like capsules or tablets, requiring their transformation into intermediate products, such as granules (18).

The granulation process of products containing high levels of dry extracts remains a difficult problem to solve, especially in the case of products obtained by spray drying using colloidal silicon dioxide as excipient. The low density and size of these products have been the major limitation for their granulation, even with the use of techniques such as fluidized bed (19). The dry granulation, even if viable, has resulted in rough products presenting porous and poor flow (19-21). Alternatively, pellets obtained by the extrusion/spheronization process are drug delivery systems that offer technological advantages, for example, 
better flow properties, less friable dosage forms, uniform size distribution, ease of coating, and uniform packing (22).

In this context, the present work was designed to develop pellets by extrusion/spheronization process, from an I. paraguariensis spray-dried powder (SDP) and characterize their chemical, physical, and technological properties, as well as to investigate the thermal and the photostability of the main polyphenol constituents present in pellets.

\section{MATERIALS AND METHODS}

\section{Chemicals}

Microcrystalline cellulose (MCC; Avicel® PH 101, Blanver, São Paulo, Brazil) and colloidal silicon dioxide (Aerosil® 200, Degussa, São Paulo, Brazil) were used as excipients. Chlorogenic acid and rutin hydrate (SigmaAldrich, Steinheim, Germany) were used as external standards. Liquid chromatography-grade methanol (Tedia, Fairfield, USA), acetic acid (Cromoline, São Paulo, Brazil), and purified water (Milli-Q system, Millipore, Bedford, MA, USA) were used for mobile phase preparation.

\section{Plant Material}

I. paraguariensis leaves and stems were supplied by the Instituto Brasileiro do Meio Ambiente-IBAMA (Ilópolis. RS, Brazil). The specimen was identified and deposited at the Herbarium of the Universidade Federal do Rio Grande do Sul (142488). The traditional method of "erva-mate" production was employed; briefly, the raw material was stabilized by roasting, and afterwards, it was dried and ground.

\section{Spray-Dried Powder Preparation}

An aqueous extractive solution (ES) was prepared by decoction of $I$. paraguariensis leaves at $96^{\circ} \mathrm{C}$ for $15 \mathrm{~min}$, at a plant:solvent ratio of 1.5:10. The ES was cooled down to $40^{\circ} \mathrm{C}$ and filtered. Colloidal silicon dioxide was added to ES at a 3:7 ratio (excipient:dry residue) and mixed for $30 \mathrm{~min}$. The resulting dispersion was spray dried using a Niro Production Minor atomizer (GEA, Copenhagen, Denmark) under the following operating conditions: $10,900 \mathrm{rpm}$ disk rotation rate, $177^{\circ} \mathrm{C}$ inlet air temperature, $99^{\circ} \mathrm{C}$ outlet air temperature, and $143 \mathrm{~mL} / \mathrm{min}$ feed flow (17). The SDP presented a moisture content of $6.64 \%$.

\section{Pellets Preparation}

Pellets formulation was composed by SDP $(40 \%, w / w)$ and MCC $(60 \%, w / w)$. Thus, $400 \mathrm{~g}$ of $I$. paraguariensis SDP and $600 \mathrm{~g}$ of MCC were blended for $5 \mathrm{~min}$ in a planetary mixer and, then, $700 \mathrm{~mL}$ of water was slowly added to the mixture under constant stirring for $15 \mathrm{~min}$. The wet mass was extruded at room temperature $\left(18-22^{\circ} \mathrm{C}\right)$ through a die of $1 \mathrm{~mm}$ in diameter at $16 \mathrm{rpm}$ (Caleva 20 extruder, Dorset, UK). The extrudate was spheronized (Caleva 250, Dorset, UK) for $4 \mathrm{~min}$ on a $22.5-\mathrm{mm}$ diameter radial cut plate rotating at $1000 \mathrm{rpm}$. The pellets were dried at $40^{\circ} \mathrm{C}$ using a fluid bed dryer (Mycrolab Hüttlin GmbH, Steinheim, Germany) until the weight loss on drying of the pellets reached $3.64 \%$ (30 $\mathrm{min})$.

\section{Pellets Characterization}

\section{Process Yield and Moisture Content}

The process yield was calculated as the difference between the theoretical weight of the formulation and the weight of pellets obtained at the end of the granulation process considering the particle size between 0.80 and $1.18 \mathrm{~mm}$. The moisture content was determined by titrimetric method (23).

\section{Particle Size Analysis}

The size distribution was determined using mechanical sieving (Haver and Bocker, Westfalen, Germany) containing a set of sieves: $0.71,0.80,0.9,1.0,1.12,1.18$, and $1.25 \mathrm{~mm}$. Samples of $10 \mathrm{~g}$ were shaken for $2 \mathrm{~min}$ with an interval of $10 \mathrm{~s}$ and amplitude of 1 . The mean diameter was determined from a cumulative percentage undersize graph.

\section{Scanning Electron Microscopy}

Photomicrographs were taken using a JEOL JSM 6060 microscope (Tokyo, Japan), at a voltage of 10 or $20 \mathrm{kV}$. Intact and cryo-fracturated pellets were previously mounted on aluminum stubs using double-sided adhesive tape and vacuum coated with a thin layer of gold. Samples were frozen by immersion, at ambient pressure for $60 \mathrm{~s}$ in liquid nitrogen to below $-160^{\circ} \mathrm{C}$, and fractured with a hammer.

\section{Density}

The density was determined using helium pycnometer (Ultrapycnometer 1000, Quantachrome Instruments, Boynton Beach, USA) by measuring the pressure difference when a known quantity of helium under pressure was allowed to flow from a precisely known reference volume into a sample cell containing pellets $(3 \mathrm{~g})$.

\section{Specific Surface Area and Pore Size Distribution/Volume}

Pellets (0.80-1.20 mm size fraction) were dried in oven for $12 \mathrm{~h}$. Afterwards, the samples were outgassed by the Autosorb-1 equipment (BET method, Quantachrome Instruments, Boynton Beach, USA) at $70^{\circ} \mathrm{C}$ for $180 \mathrm{~min}$. After cooling the tubes, the surface area was analyzed by the same instrument. Nitrogen was added in known quantities into the evacuated tube containing the sample. A gradual increase in the quantity of nitrogen gas increased the pressure in the sample tube. When the pressure in the tube had equilibrated following each introduction of nitrogen gas, the pressure was recorded. The pressure data were used, in turn, to calculate the volume of gas adsorbed. The volume of gas adsorbed was measured as a function of relative pressure. Relative pressure was the ratio between the pressure in the sample tube and the saturation vapor pressure of the adsorbate gas (i.e., the pressure at which the adsorbate gas liquefies). The saturation pressure was measured for every sample tube pressure data 
point. The surface area and pore size/volume parameters were calculated from the isotherm data.

\section{Hausner's Ratio and Carr's Index}

The density parameters of the SDP were determined using $10.0 \mathrm{~g}$ of sample in a $50-\mathrm{mL}$ graduated cylinder mounted on a mechanical tapping device (24) (J. Engelsmann AG, Ludwigshafen, Rhein, Germany). The bulk density was calculated as the ratio between the sample weight $(\mathrm{g})$ and the initial volume $(\mathrm{mL})$, and the tapped density as the ratio between the sample weight $(\mathrm{g})$ and the final volume $(\mathrm{mL})$. The Carr's index (25) and the Hausner's ratio (26) were calculated according to the following equations:

Carr'sindex $(\%)=\frac{(\text { Tapped density-Bulk density })}{\text { Tapped density }} \times 100$

Hausner's ratio $=\frac{\text { Tapped density }}{\text { Bulk density }}$

\section{Angle of Repose}

The angle of repose (23) of the SDP was measured according to the following equation:

$\operatorname{Tg} \theta=h / r$

where $\operatorname{Tg} \theta$ is the tangent of the angle of repose, $h$ is the height, and $r$ is the radius.

\section{Liquid Chromatography Analysis}

\section{Chromatographic Conditions}

The liquid chromatography (LC) analysis was performed as described by Silva and cols. (27), using a Shimadzu Prominence equipment (Kyoto, Japan) coupled to a SPD-20A UVVis detector. The stationary phase was a Shimadzu RP-18 column (CLC-ODS (M) $250 \times 4.6 \mathrm{~mm}$ i.d., $5 \mu \mathrm{m}$ particle size) guarded by a Waters precolumn $(20 \times 3.9 \mathrm{~mm}$ i.d., $10 \mu \mathrm{m}$ particle size). The mobile phase consisted of (A) acetic acid $2.0 \%$ $(v / v)$ and $(\mathrm{B})$ methanol:water $(85: 15, w / w)$. The gradient elution was $31 \% \mathrm{~B}(0-10 \mathrm{~min}), 31-56 \% \mathrm{~B}(10-25 \mathrm{~min}), 56 \% \mathrm{~B}$ (25-33 min), 56-77\% B (33-45 min), 77-56\% B (45-50 min), and $56-31 \% \mathrm{~B}$ until $60 \mathrm{~min}$. The flow rate was $0.7 \mathrm{~mL} / \mathrm{min}$ and the injection volume was $20 \mu \mathrm{L}$. The detection wavelength was $340 \mathrm{~nm}$, and the analysis was carried out at room temperature.

\section{Standard Curves}

Chlorogenic acid (CA) and rutin (RU) were used as external standards. They were dissolved in methanol:water $(50: 50, v / v)$ and diluted to obtain the concentrations of 2.0, $4.0,6.0,8.0$, and $10.0 \mu \mathrm{g} / \mathrm{mL}$. These solutions were filtered through a $0.45-\mu \mathrm{m}$ membrane filter (Millipore, HVLP). The linear equations $(n=5)$ were $y=67,255 x-13,006\left(r^{2}=0.9993\right)$ and $y=43,584 x-7053.5\left(r^{2}=0.9991\right)$ for CA and RU, respectively.

\section{Sample Preparations}

Pellets $(136.5 \mathrm{mg}$ ) were dispersed in $50.0 \mathrm{~mL}$ of water. From this colloidal dispersion, an aliquot of $2.0 \mathrm{~mL}$ was diluted to $10.0 \mathrm{~mL}$ with a mixture of methanol:water $(50: 50, v / v)$. The resulting solution was filtered through a $0.45-\mathrm{mm}$ membrane (Millipore, HVLP) and analyzed by LC, taking into account pellet residual moisture determined by titrimetric method (23). For the stability tests, the moisture content was determined before the LC analysis for samples collected in each time. The content of neo-chlorogenic acid, cryptochlorogenic acid, P4, P5, and P6 in the samples was determined using CA calibration curve, since they exhibit UV spectra pattern of caffeoylquinic acid derivatives with UV max absorption bands at $328 \mathrm{~nm}$ (27). The content of RU was calculated by the corresponding equation. Total polyphenol content in the samples was obtained by the sum of the content of neo-chlorogenic acid, chlorogenic acid, cryptochlorogenic acid, P4, P5, and P6.

\section{Method Validation}

The LC method was validated for specificity, linearity, precision (repeatability and intermediary precision), accuracy, and detection and quantitation limits (28). The specificity was evaluated by analyzing blank pellets containing only the excipients (colloidal silicon dioxide and microcrystalline cellulose), and the polyphenols were identified based on their UV spectra between 200 and $400 \mathrm{~nm}$ and their retention times. The accuracy of the method was evaluated by spiking known amounts of CA and RU standards at three different concentration levels $(1.0,5.0$, and $10.0 \mu \mathrm{g} / \mathrm{mL})$ into blank pellet solution (methanol:water, $50 \%, v / v$ ). At each level, samples were prepared in triplicate and analyzed by LC. The accuracy in the presence of the matrix was determined by subtracting the measured amount of polyphenols from the spiked amount, divided by spiked amount, and multiplied by 100 .

The method was specific (data not shown) and the regression coefficients were $r^{2}=0.9998$ for CA and $r^{2}=0.9999$ for RU standard curves. When the standard was spiked into blank pellet solution, the regression coefficient was similar. The relative standard deviations (R.S.D.) of the slope from the three calibration curves were 0.33 and $0.21 \%$, respectively, for CA and RU solutions (methanol:water, $50 \%, v / v$ ) and 0.63 and $0.45 \%$, respectively, for CA and RU into spiked blank pellet solution ( $2.73 \mathrm{mg} / \mathrm{mL}$, aqueous solution). The curve equations were, respectively, $y=80,789.9 x-13,046.6, y=44,240.1 x-2887.5, y=$ $868.2 x-93.74 .2$, and $y=193.6 x-1241.9$, where $y$ is the peak area and $x$ is the concentration of the external standards. The observed repeatability (R.S.D. $=0.43 \%$ for CA; R.S.D. $=3.20 \%$ for RU) and the intermediate precision (R.S.D. $=0.50 \%$ for CA; R.S.D. $=1.36 \%$ for RU) were adequate. The recovery of CA (96.8 to $102.2 \%$ ) and RU (99.3 to $100.5 \%$ ) from blank pellet solution showed that the method was accurate and that the pellet excipients did not influence the analysis. The LOD and LOQ of CA $(0.157$ and $0.162 \mu \mathrm{g} / \mathrm{mL}$, respectively) and RU (0.093 and $0.094 \mu \mathrm{g} / \mathrm{mL}$, respectively) showed the excellent sensitivity of the method. 


\section{Dissolution Test}

The in vitro dissolution test of pellets presenting size range between 0.80 and $1.18 \mathrm{~mm}$ was carried out according to the USP 31 apparatus II procedure (Pharmatest PTWS II, Hainburg, Germany), using a paddle speed of $75 \mathrm{rpm}$ and $700 \mathrm{~mL}$ of dissolution media at $37 \pm 0.5^{\circ} \mathrm{C}(n=6)(23)$. The following dissolution media were employed: purified water (pH 5.5), HCl $0.1 \mathrm{~N}$ ( $\mathrm{pH} 1.2$ ), or phosphate buffer ( $\mathrm{pH} 6.8)$. Aliquots $(5 \mathrm{~mL})$ of the dissolution media were manually taken after $5,15,30,45$, and $60 \mathrm{~min}$, filtered through a $0.45-\mu \mathrm{m}$ membrane (Millipore, HVLP), and analyzed using the above-described LC method.

\section{Stability}

\section{Photostability}

The photostability test was carried out according to the ICH (29). Pellets were exposed to UVC radiation (Light express LE UV, $254 \mathrm{~nm}, 30 \mathrm{~W}$ ) at three different storage conditions: amber glass bottles, transparent glass bottles, or open dishes. The lamp was fixed to a chamber $(100 \times 16 \times$ $16 \mathrm{~cm}$ ) in a horizontal position, at a distance of approximately $10 \mathrm{~cm}$. The chamber was internally coated with mirrors, in order to distribute the radiation uniformly. A sample wrapped in aluminum foil was used as a dark control to evaluate the influence of temperature into the chamber (approximately $27^{\circ} \mathrm{C}$ ) on pellet stability. The polyphenol content in the samples was measured in triplicate $0,12,24$, and $48 \mathrm{~h}$ after irradiation using the above-described LC method.

\section{Thermal Stability Test}

The thermal stability test was carried out at $40 \pm 2^{\circ} \mathrm{C}$ and 75 $\pm 5 \%$ relative humidity for 6 months to evaluate the stability of the polyphenols under accelerated conditions $(30,31)$. The pellets were conditioned in transparent glass bottles or polyethylene ethyl (PET) bottles (semipermeable material). The polyphenol content in the samples was measured in triplicate at $0,1,2,3,4,5$, and 6 months after exposition in a climatic chamber (Nova Ética, SP, Brazil) using the above-described LC method. This condition was chosen to evaluate the effect of temperature and relative humidity on the stability of the polyphenols.

\section{Statistical Analysis}

The results were analyzed either by Student's test or by the analysis of variance (ANOVA) followed by Tukey's test for significance at $p$ values less than 0.05 .

\section{RESULTS}

\section{Physical, Chemical, and Technological Characterization of the Pellets}

Table I and Fig. 1 show the main technological characteristics of the pellets, as process yield $(78.7 \%)$, residual moisture $(3.64 \%)$, and spherical shape.
Table I. Technological Characterization of Pellets Containing $40 \%$ of Spray-Dried Powder and $60 \%$ of Microcrystalline Cellulose

Technological parameters

Yield (\%) 78.7

Moisture content (\%)

Mean diameter $(\mathrm{mm})$

1.10

Apparent density $(\mathrm{mg} / \mathrm{mL})$

1.60

Specific surface area $\left(\mathrm{m}^{2} / \mathrm{g}\right) \quad 6.92$

$\begin{array}{lr}\text { Pore } \operatorname{size}^{a}(\AA) & 2.95\end{array}$

Pore volume $\left(10^{-3} \mathrm{~cm}^{2} / \mathrm{g}\right) \quad 10.21$

Hausner's ratio $\quad 1.00$

Carr's index (\%) $\quad 0.34$

Angle of repose $\quad 26$

${ }^{a}$ Total pore volume for pores with radius lower than $188.40 \AA$ at $P /$ $P_{\mathrm{o}}=0.946298$

The particle size distribution of a powder is a parameter which expresses the relative amount (\%) of particles distributed within a particle size range. It was determined by analyzing the particle size of the pellets using different nominal mesh sieves. The percentages of retained particles were $20.3 \%$ $(1.25 \mathrm{~mm}), 18.6 \%(1.18 \mathrm{~mm}), 21.2 \%$ (1.12 mm), $24.4 \%$ (1.0 mm), 12.4\% (0.9 mm), 2.1\% (0.8 mm), 0.8\% (0.71 mm), and $0.2 \%$ (pan). Therefore, the pellets were produced within the range of 0.80 and $1.18 \mathrm{~mm}$ (mean diameter of $1.10 \mathrm{~mm}$ ).

The polyphenol LC profile of pellets is presented in Fig. 2. The presence of peaks with the retention time (Rt) of the four polyphenols previously identified by Silva and cols. (27) is observed, neo-chlorogenic acid-NCA (Rt $6.97 \mathrm{~min}$ ), chlorogenic acid-CA (Rt $10.84 \mathrm{~min}$ ), crypto-chlorogenic acid-CCA (Rt $11.62 \mathrm{~min}$ ), and rutin-RU (Rt $30.36 \mathrm{~min}$ ). The non-identified peaks referred by Silva and cols. (27), P4 (Rt $27.02 \mathrm{~min}$ ), P5 (Rt $27.68 \mathrm{~min}$ ), and P6 (Rt $30.85 \mathrm{~min}$ ), corresponding probably to isomeric dicaffeoyl esters of quinic acid (i.e., 3,4- $O$-dicaffeoyl, 4,5- $O$-dicaffeoyl, 3,5-O-dicaffeoyl, or 1,5-O-dicaffeoyl esters), could be also observed. Table II shows the polyphenol content of the SDP and the corresponding recovery in pellets.

\section{Dissolution Test}

The release profiles of pellets in different media are presented in Fig. 3. In water ( $\mathrm{pH} 5.5$ ), the maximum dissolution of the polyphenols, individually, was in the range of 89.44 and $100.05 \%$, where only RU reached $100 \%$ (Fig. 3a). In acid (pH 1.2) (Fig. 3b) and buffer medium ( $\mathrm{pH}$ 6.8), all the polyphenols presented low release (Fig. 3c).

\section{Photostability}

The polyphenol content of pellets after exposition to $\mathrm{UVC}$ radiation is shown in Fig. 4. After $48 \mathrm{~h}$ of exposure, no significant change was detected in the LC profile. The polyphenols were stable against light when conditioned in amber glass and control bottles; however, after $48 \mathrm{~h}$ of exposure, the polyphenol content of pellets was reduced $(p<0.05)$ when the samples were stored in open dishes or in transparent glass bottles. In open dishes, NCA, CA, CCA, P4, P5, and P6 contents showed significant reduction over the time of the 

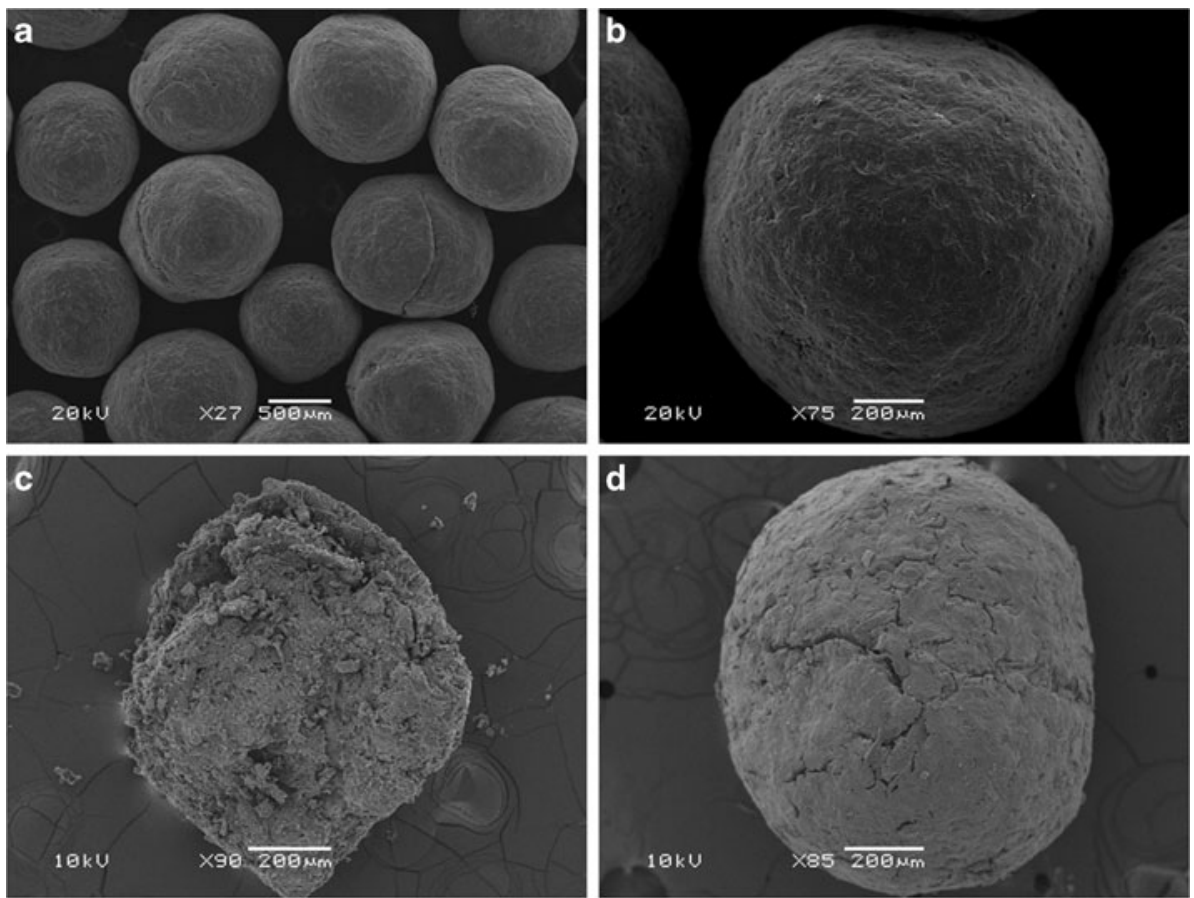

Fig. 1. Photomicrograph of pellets. a Pellets with $\times 27$ magnification; b pellets with $\times 75$ magnification; c cryo-fracturated pellets with $\times 90$ magnification; d pellets after dissolution test with $\times 85$ magnification

experiment. In transparent glass bottles, only NCA, CA, CCA, and P6 were unstable after $48 \mathrm{~h}$ of exposure to light. The moisture content of all samples presented no significant difference $(p<0.05)$ during the photostability test (data not shown).

\section{Accelerated Testing}

The results of pellets accelerated testing are presented in Figs. 5 and 6. Pellets showed to be hygroscopic, increasing their residual humidity when conditioned in PET bottles. After 6 months, the moisture content of the samples stored in PET bottles increased from 3.64 to $6.83 \%$ and their color became brown. Pellet samples stored in transparent glass bottles presented no significant difference $(p<0.05)$ in the moisture content over the accelerated testing (data not shown), but their color became brown too. When the pellets were stored in transparent glass bottles (impermeable material), all polyphenols evaluated presented a significant decrease $(p<0.05)$ in their content. After 6 months, the percentages of degradation were $33.5 \%$ (NCA), $29.5 \%$ (CA), $27.4 \%$ (CCA), $40.1 \%$ (P4), 39.1\% (P5), 19.5\% (RU), and 34.2\% (P6). The total polyphenol content of pellets decreased from 199.4 to

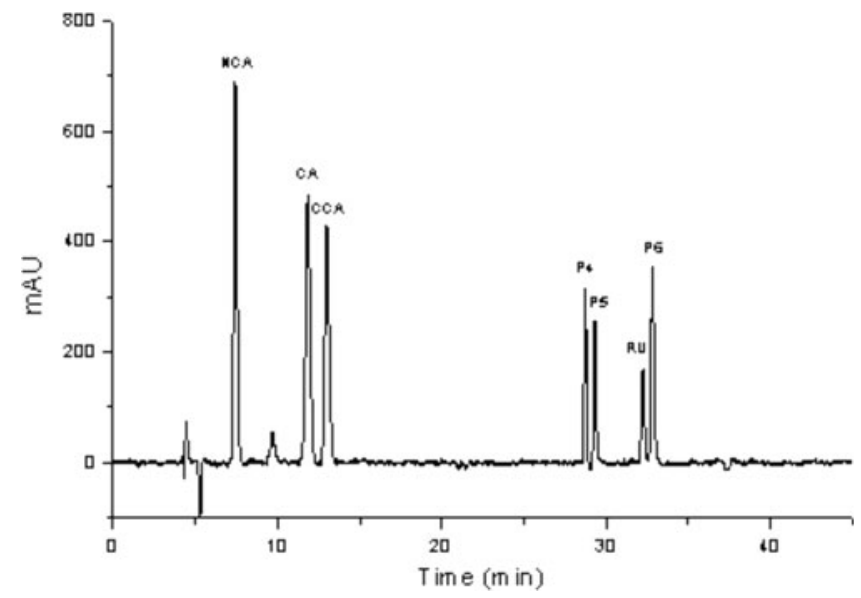

Fig. 2. Chromatographic profile of pellets. $N C A$ neo-chlorogenic acid; $C A$ chlorogenic acid; $C C A$ crypto-chlorogenic acid; $R U$ rutin; $P 4, P 5$, and $P 6$ isomeric dicaffeoyl esters of quinic acid 
Table II. Polyphenol Content of Spray-Dried Powder (SDP) and Pellets $(n=3)$

\begin{tabular}{lccc}
\hline Peaks & SDP $(\mathrm{mg} / \mathrm{g})(\bar{X} ;$ S.D. $)$ & $\begin{array}{l}\text { Pellets }(\mathrm{mg} / \mathrm{g}) \\
(\bar{X} ; \text { S.D. })\end{array}$ & Recovery $(\%)$ \\
\hline $\mathrm{NCA}^{a}$ & $49.74(0.02)$ & $47.97(0.12)$ & 96.4 \\
$\mathrm{CA}$ & $43.63(0.29)$ & $43.41(0.01)$ & 99.5 \\
$\mathrm{CCA}^{a}$ & $41.52(0.02)$ & $41.39(0.67)$ & 99.7 \\
$\mathrm{P}^{a}$ & $20.05(0.36)$ & $19.21(0.07)$ & 95.8 \\
P5 $^{a}$ & $16.10(0.52)$ & $14.91(0.33)$ & 92.6 \\
RU $_{\text {P6 }^{a}}$ & $15.85(0.45)$ & $13.14(0.23)$ & 82.9 \\
Total $^{b}$ & $22.62(0.08)$ & $19.37(0.33)$ & 85.6 \\
\hline
\end{tabular}

$N C A$ neo-chlorogenic acid, $C A$ chlorogenic acid, $C C A$ cryptochlorogenic acid, $R U$ rutin, $S D P$ spray-dried powder, S.D. standard deviation

${ }^{a}$ Calculated by the chlorogenic acid linear equation

${ }^{b}$ Sum of neo-chlorogenic acid, chlorogenic acid, crypto-chlorogenic acid, P4, P5, and P6 concentrations

$136.5 \mathrm{mg} / \mathrm{g}$. In the same way, when the pellets were stored in PET bottles (semipermeable material), all polyphenols evaluated presented a significant decrease $(p<0.05)$ in their content; after 6 months, the percentages of degradation were $55.5 \%(\mathrm{NCA}), 33.32 \%(\mathrm{CA}), 20.2 \%$ (CCA), $51.8 \%$ (P4), 61.4\% (P5), 67.4\% (RU), and 37.3\% (P6). The total polyphenol content of pellets decrease from 199.40 to $114.8 \mathrm{mg} / \mathrm{g}$.

\section{送}
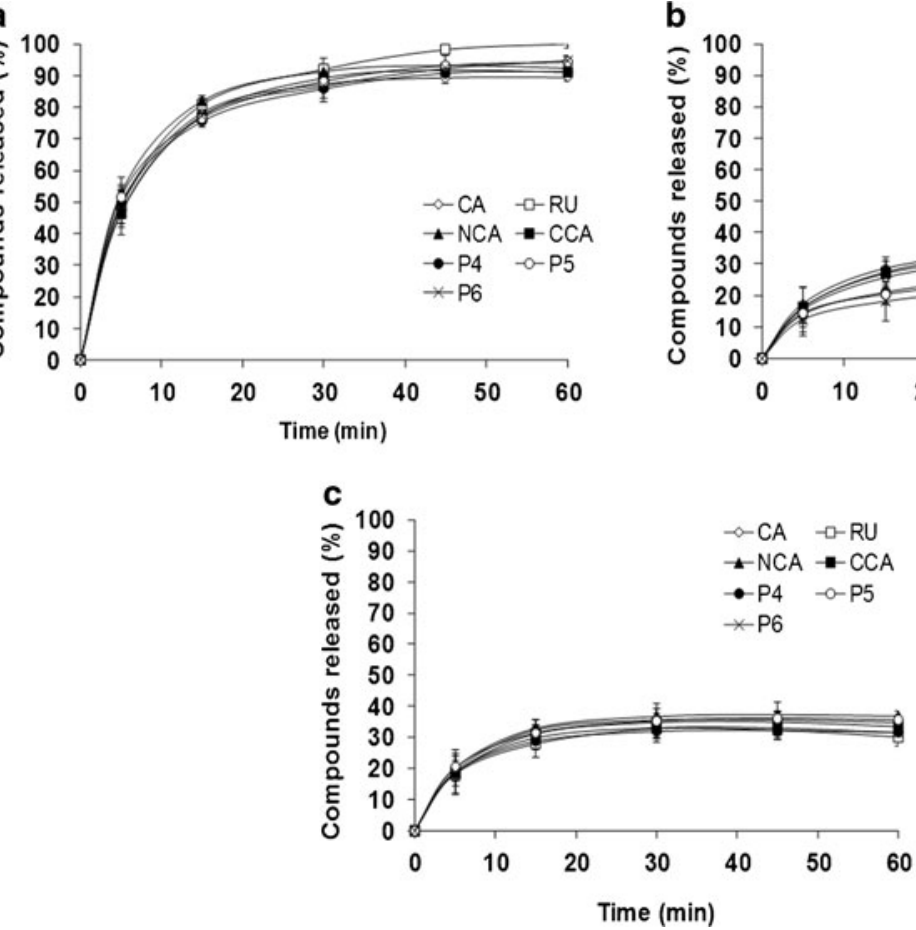

Fig. 3. Pellets dissolution profile $(n=6)$. a Release profile in water $(\mathrm{pH} 5.5)$; b release profile in $\mathrm{HCl} 0.1 \mathrm{~N}$ ( $\mathrm{pH}$ 1.2); c release profile in buffer phosphate ( $\mathrm{pH}$ 6.8). NCA neo-chlorogenic acid; $C A$ chlorogenic acid; $C C A$ crypto-chlorogenic acid; $R U$ rutin; $P 4, P 5$, and $P 6$ isomeric dicaffeoyl esters of quinic acid

\section{DISCUSSION}

\section{Pellet Physical Characterization and Polyphenol Content} ules while they were rotating in the spheronizer. equal parts of MCC.

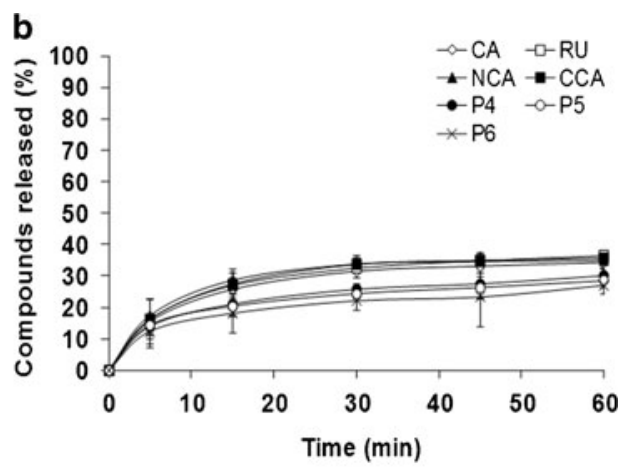

The extrusion and spheronization process of the SDP required about $70 \%$ of water (percentage of the total weight of solid raw materials) in order to obtain a wet mass with a suitable consistency to extrudate. During the spheronization step, in order to avoid the agglomeration of the spheroidal granules, $0.5 \%$ of MCC was sprinkled on the spheroidal gran-

Taking into account the total weight of the wet mass, the percentage of water necessary to obtain a wet mass with a suitable consistency was about $41 \%$, which is in agreement with a previous study of Lustig-Gustafsson and cols. (32). The authors investigated the influence of the water content of the wet mass on the formation and properties of pellets composed by eight non-related drugs of different solubility (boric acid, glycine, glucose, ascorbic acid, caffeine, two batches of lactose monohydrate, paracetamol, and 5-aminosalicylic acid) and verified that the optimum water content of the wet mass necessary to form round pellets with a narrow particle size distribution was in the range of 30 to $40.6 \%$ and is a function of the solubility of the model drugs when incorporated into

Pelletization seemed to occur by the mechanism described by Rowe (33), because some granules presented a scar right in the center, which can be considered a transitional form between the dumbbell and the spheroid shape. According to this author, the extrudate broke on the friction plate of the spheronizer into small cylinders which went through several 

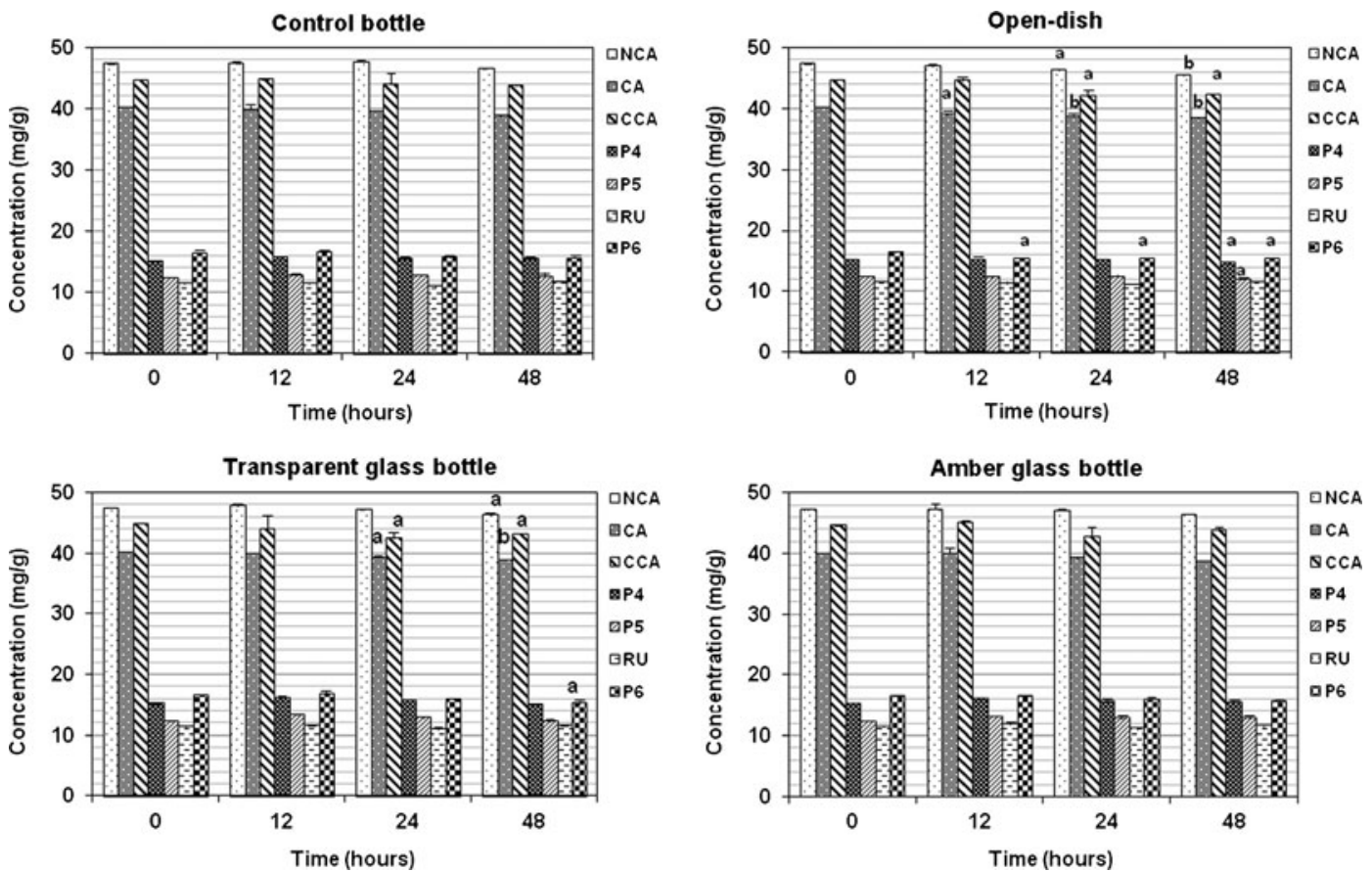

Fig. 4. Polyphenol content of pellets after $48 \mathrm{~h}$ of exposure to UVC radiation $(n=3)$. $N C A$ neo-chlorogenic acid; $C A$ chlorogenic acid; $C C A$ crypto-chlorogenic acid; $R U$ rutin; $P 4, P 5$, and $P 6$ isomeric dicaffeoyl esters of quinic acid; significant statistical differences were determined by Tukey's test $(p<0.05)$; differences between the concentrations over time $(h)$ were represented by letters $(a, b)$

shape changes, i.e., cylinders with rounded ends, dumbbells, ellipsoids, and finally spheroids, which could be evidenced by the photomicrographs (Fig. 1).

Despite the addition of MCC to avoid pellet agglomeration in the spheronization process, the pellets presented a mean diameter of $1.1 \mathrm{~mm}$, high yield $(78.7 \%)$, and residual moisture content $(3.6 \%)$, characteristics which become this product appropriated for obtention of derivative forms, as tablets or capsules, or as final product (sachets).

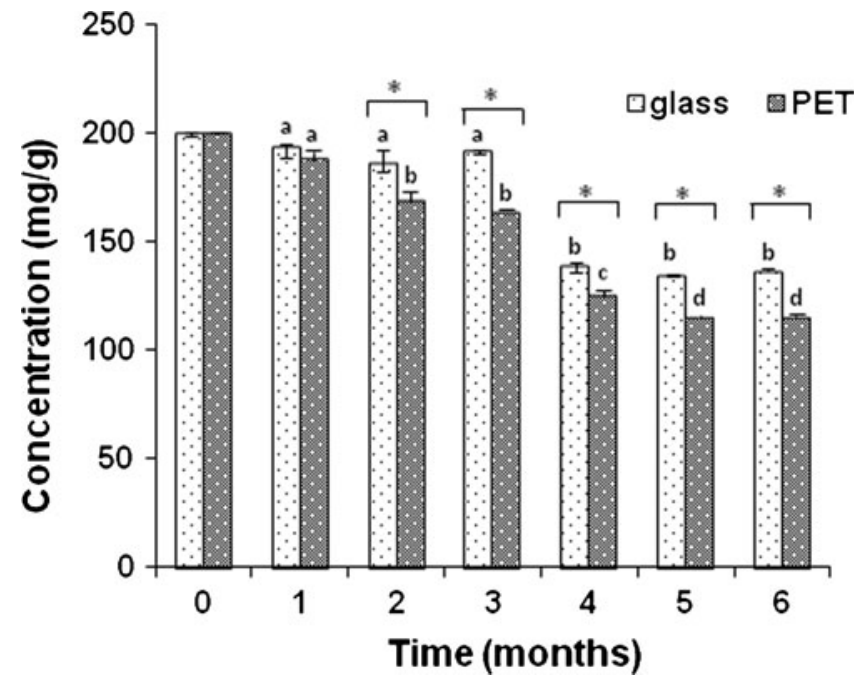

Fig. 5. Total polyphenol content of pellets under accelerated condition $\left(40^{\circ} \mathrm{C} / 75 \%\right.$ relative humidity $/ 6$ months) $(n=3)$. Glass stored in transparent glass bottles; PET stored in polyethylene ethyl bottles; significant statistical differences were determined by Tukey's test $(p<0.05)$; differences between glass and PET bottles were represented by an asterisk, while differences over time (months) were represented by letters $(a, b, c, d)$ 

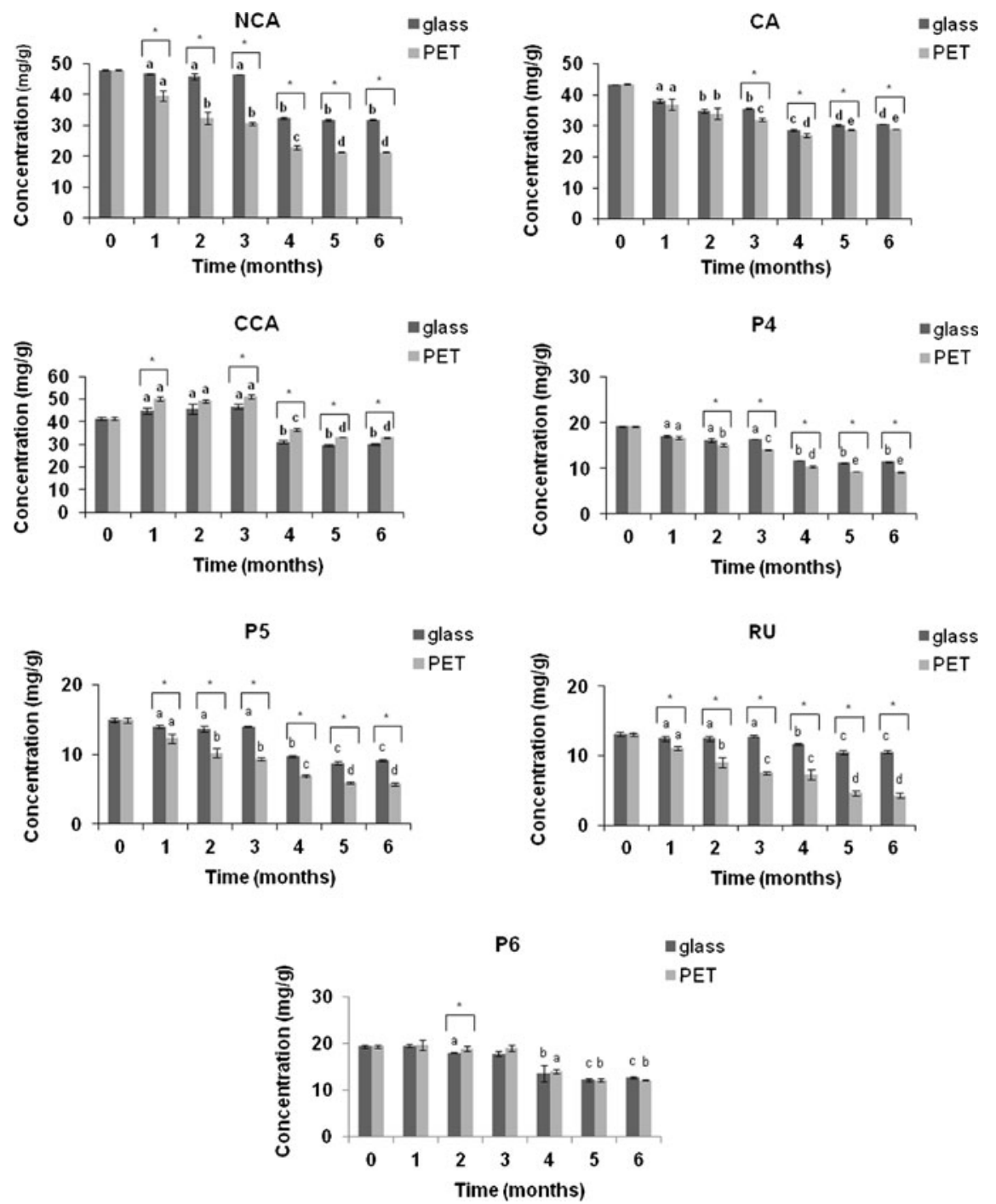

Fig. 6. Polyphenol content of pellets under accelerated condition $\left(40^{\circ} \mathrm{C} / 75 \%\right.$ relative humidity/ 6 months) (n=3). NCA neo-chlorogenic acid; $C A$ chlorogenic acid; $C C A$ crypto-chlorogenic acid; $R U$ rutin; $P 4, P 5$, and $P 6$ isomeric dicaffeoyl esters of quinic acid; Glass stored in transparent glass bottles; $P E T$ stored in polyethylene ethyl bottles; significant statistical differences were determined by Tukey's test $(p<0.05)$; differences between glass and PET bottles were represented by an asterisk, while differences over time (months) were represented by letters $(a, b, c, d)$

Three commonly reported methods for testing the pellet flow properties were applied: the Carr's index (CI), the Hausner's ratio (HR), and the angle of repose (23). A CI below 15, an HR lower than 1.25, and an angle of repose lower than 30 characterize free-flowing materials. Based on the results, the pellets could be classified as a material with good flow properties.

The polyphenol content in SDP was compared to that found in the corresponding pellets, taking into account the moisture content of both. Individually, the polyphenol present in the pellets were in a range of 82.9 to $99.7 \%$ that present in SDP. The total polyphenol (sum of neo-chlorogenic acid, chlorogenic acid, crypto-chlorogenic acid, P4, P5, and P6 contents) in the pellets reached a value higher than $95 \%$ that contained in SDP, what can be considered an excellent result considering the lability of this class of compounds and the complex herbal matrix.

\section{Dissolution Test}

After the dissolution test, pellets remained intact and separated without swelling. It is well known that MCC, when extruded and spheronized, loses its swelling properties. In this way, pellets will only disintegrate if the amount of drug is larger than the MCC capacity of keeping the pellet structure. In MCC pellets with higher amount of excipient, the watersoluble drug is washed out of pellets leaving pores in the structure (34). This could be seen in the photomicrographs presented in Fig. 1d, where pores were found in the pellets after the dissolution test. In this case, the MCC would act as a 
matrix/reservoir and the extract would be released by diffusion.

In acid medium ( $\mathrm{pH} 1.2$ ), all the polyphenols presented low release (Fig. 3b), as we could expect for compounds with weak acid characteristics. Unexpectedly, a similar behavior was also observed in a buffer medium ( $\mathrm{pH}$ 6.8) (Fig. 3c), denoting that other factors were involved. Since sink condition has been respected for all dissolution media (CA solubility $=$ $25 \mathrm{mg} / \mathrm{mL}$ at $25^{\circ} \mathrm{C}$ in water; RU solubility $=0.12 \mathrm{mg} / \mathrm{mL}$ at $25^{\circ} \mathrm{C}$ in water), we checked the stability of the polyphenols into dissolution media ( $\mathrm{pH} 1.2$ and 6.8). No degradation of polyphenols was observed in both media since the samples remained stable for 3 days at $24^{\circ} \mathrm{C}$ (data not shown). We are looking for an explanation for this phenomenon, being the effect of the salts from the buffer solution or lack of release from the MCC matrix in this $\mathrm{pH}$ cannot ruled out.

\section{Photostability}

After $48 \mathrm{~h}$ of exposition to UVC radiation, the polyphenol content of pellets was reduced $(p<0.05)$ when the samples were stored in open dishes or in transparent glass bottles. However, in a previous report (17), we demonstrated that the polyphenols present in SDP raw material showed to be stable against light over the time under the same conditions employed in the present study. In that study, we suggested that the protective effect was provided by the use of colloidal silicon dioxide as excipient because of its ability to reflect/ scatter UV and visible radiations (35). Considering this, the sensibility of the polyphenols from pellets could be related to the new structure of the matrix produced by the addition of MCC, granulation with water, extrusion, and spheronization.

\section{Accelerated Testing of Stability}

In order to evaluate the influence of the temperature and relative humidity on the polyphenol stability, two different types of packaging material were tested: transparent glass bottles (impermeable material) and PET bottles (semipermeable material). After 6 months, the content of all polyphenols evaluated presented a significant decrease $(p<0.05)$ in both conditions (transparent glass and PET bottles). However, the reduction of polyphenol content was more prominent in the pellets stored in PET bottles, especially for NCA, P4, P5, and $\mathrm{RU}$, which presented a degradation superior to $50 \%$ of the initial concentration.

These results were very similar to that obtained in a previous study (17) where the stability of SDP was evaluated under the same conditions. According to that study, after 4 months, the samples conditioned in PET bottles presented an increase in the residual moisture content (6.64 to $13.96 \%$ ) and the polyphenols of the SDP were more degraded than that samples stored in impermeable glass bottles. According to the authors, the degradation of polyphenols in SDP could be associated to the residual moisture content, since the degradation was more pronounced in the samples which presented high residual moisture content. The presence of water could facilitate the occurrence of the residual activity of the peroxidases, a very thermostable enzyme present in the $I$. paraguariensis raw material $(36,37,38)$.
The CCA concentration showed an anomalous increase in the first months, when pellets were stored in both transparent glass and PET bottles. After that, CCA concentration decreased significantly $(p<0.05)$, until the sixth month, to a concentration lower than the initial. This phenomenon was also observed in our previous study (17).

\section{CONCLUSION}

The feasibility of pellets from an I. paraguariensis spraydried powder using extrusion/spheronization technique is being demonstrated opening possibilities for new products from this traditional raw material in both, pharmaceutical and food fields. The pellets exhibited adequate size, spherical shape, and very good yield. When stored in amber in tight amber glass bottles, the total polyphenol were stable against the exposure to UVC radiation for $48 \mathrm{~h}$. In contrast, the polyphenols demonstrated to be sensible to the temperature, especially when the residual moisture is high what indicate the need of conditioning it in opaque and humidity tight packing under low temperatures.

\section{ACKNOWLEDGMENTS}

The authors are grateful to Coordenação de Aperfeiçoamento de Pessoal de Nível Superior (CAPES) and to Conselho Nacional de Desenvolvimento Científico e Tecnológico $(\mathrm{CNPq})$ for the financial support and the scholarships.

\section{REFERENCES}

1. Filip R, Lotito SB, Ferraro G, Fraga CG. Antioxidant activity of Ilex paraguariensis and related species. Nutr Res. 2000;20:143746. doi:10.1016/S0271-5317(00)80024-X.

2. Schinella GR, Troiani G, Dávila V, Buschiazzo P, Tournier HA. Antioxidant effects of an aqueous extract of Ilex paraguariensis. Biochem Biophys Res Commun. 2000;269:357-60. doi:10.1006/ bbrc.2000.2293.

3. Gugliucc AE, Menini T. The botanical extracts of Achyrocline satureioides and Ilex paraguariensis prevent methylglyoxalinduced inhibition of plasminogen and antithrombin III. Life Sci. 2002;72:279-92. doi:10.1016/S0024-3205(02)02242-7.

4. Lunceford N, Gugliucci A. Ilex paraguariensis extracts inhibit AGE formation more efficiently than green tea. Fitoterapia. 2005;76:419-27. doi:10.1016/j.fitote.2005.03.021.

5. Mosimann P, Wilhelm-Filho AL, Da Silva EL. Aqueous extract of Ilex paraguariensis attenuates the progression of atherosclerosis in cholesterol-fed rabbits. BioFactors. 2006;26:59-70. doi:10.1002/biof.5520260106.

6. Pang J, Choi Y, Park T. Ilex paraguariensis extract ameliorates obesity induced by high-fat diet: potential role of AMPK in the visceral adipose tissue. Arch Biochem Biophys. 2008;476:178-85. doi:10.1016/j.abb.2008.02.019.

7. Filip R, Ferraro GE. Researching on new species of "Mate": Ilex brevicuspis: phytochemical and pharmacology study. Eur J Nutr. 2003;42:50-4. doi:10.1007/s00394-003-0399-1.

8. Gonzalez A, Ferreira F, Vazquez A, Moyna P, Paz EA. Biological screening of Uruguayan medicinal-plants. J Ethnopharmacol. 1993;39:217-20. doi:10.1016/0378-8741(93)90040-C.

9. Bracesco N, Dell M, Rocha A, Behtash S, Menini T, Gugliucci A, et al. Antioxidant activity of a botanical extract preparation of Ilex paraguariensis: prevention of DNA double-strand breaks in Saccharomyces cerevisiae and human low-density lipoprotein 
oxidation. J Alter Complement Med. 2003;9:379-87. doi:10.1089/ 107555303765551606.

10. Miranda DDC, Arcxari D, Pedrazzoli J, Carvalho PO, Cerutti $\mathrm{SM}$, Bastos DHM, et al. Protective effects of maté tea (Ilex paraguariensis) on $\mathrm{H}_{2} \mathrm{O}_{2}$-induced DNA damage and DNA repair in mice. Mutagenesis. 2008;23:261-5. doi:10.1093/mutage/gen011.

11. Gugliucci AE, Stahl AJC. Low density lipoprotein oxidation is inhibited by extracts of Ilex paraguariensis. Biochem Mol Biol Int. 1995:35:47-56.

12. Ramirez-Mares M, Chandra S, Mejia EG. In vitro chemopreventive activity of Camellia sinensis, Ilex paraguariensis and Ardisia compressa tea extracts and selected polyphenols. Mutat Res Fundam Mol. 2004;554:53-65. doi:10.1016/j.mrfmmm.2004.03.002.

13. Oliveira D, Freitas HS, Souza MFF, Arçari DP, Ribeiro ML, Carvalho PO, et al. Yerba Maté (Ilex paraguariensis) aqueous extract decreases intestinal SGLT1 gene expression but does not affect other biochemical parameters in alloxan-diabetic Wistar rats. J Agric Food Chem. 2008;56:10527-32. doi:10.1021/ jf8021404.

14. Matsumoto RT, Bastos DM. Effects of Maté tea (Ilex paraguariensis) ingestion on mRNA expression of antioxidant enzymes, lipid peroxidation, and total antioxidant status in healthy young women. J Agric Food Chem. 2009;57:1775-80. doi:10.1021/jf803096g.

15. Campos AM. Desenvolvimento de extratos secos nebulizados de Ilex paraguariensis St. Hil., Aquifoliaceae (erva-mate) [Ph.D. Thesis]. Porto Alegre, Brazil: Universidade Federal do Rio Grande do Sul; 1996.

16. Gnoatto SCB. Metodologias analíticas para quantificação de marcadores químicos em preparações de Ilex paraguariensis (A. St. Hil.) e Desenvolvimento de extrato seco por nebulização. [M.Sc. Thesis]. Porto Alegre, Brazil: Universidade Federal do Rio Grande do Sul; 2002.

17. Yatsu FKJ, Borghetti GS, Bassani VL. Technological characterization and stability of Ilex paraguariensis St. Hil. Aquifoliaceae (Maté) spray-dried powder. J Med Food. 2011;14:413-9. doi:10.1089/jmf.2010.0044.

18. Souza TP, Bassani VL, Ortega GG, Dalla Costa TC, Petrovick PR. Influence of adjuvants on the dissolution profile of tablets containing high doses of spray-dried extract of Maytenus ilicifolia. Pharmazie. 2001;56:730-3.

19. Petrovick GF, Petrovick PR, Bassani VL. Granulação e revestimento em leito fluidizado. Cad Farm. 2006;21:107-18.

20. Couto AG. Desenvolvimento e avaliação tecnológica de granulado contendo alto teor de produto seco nebulizado de Phyllanthus niruri (Euphorbiacea) - quebra-pedra, [M.Sc. Thesis]. Porto Alegre, Brazil: Universidade Federal do Rio Grande do Sul; 2000.

21. Souza TP, Ortega GG, Petrovick PR, Bassani VL. Avaliação da viabilidade de compressão direta de formulações contendo alto teor de produto seco nebulizado de Maytenus ilicifolia. Acta Farm Bonaer. 2000;19:91-8.

22. Reynolds AD. A new technique for the production of spherical particles. Manuf Chem Aerosol News. 1970;41:40-3.

23. USP 31, The United States Pharmacopeia. United States Pharmacopeial Convention Inc: Rockville, MD; 2009.
24. Guyot JC, Arnaud P, Becourt P, Cassiere JP, Chulia D, Duchêne $\mathrm{D}$, et al. Commentaires relatifs aux méthodes générales d'analyse des formes orales solides récemment introduites dans les pharmacopées française et européenne. Rapport d'une commission SFSTP. STP Pharma Prat. 1995;5:482-94.

25. Carr RL. Evaluating flow properties of solids. Chem Eng. 1965;72:163-8.

26. Hausner HH. Friction conditions in a mass of metal powder. Int $\mathbf{J}$ Powder Metall. 1967:3:7-13.

27. Silva FA, Pavei C, Ortega GG, Lima EM, Diniz DGA, Moreira $\mathrm{JCF}$, et al. Validation of a LC method for polyphenol assay in extractive solutions from Ilex paraguariensis (Maté). J Liq Chromatogr Relat Technol. 2007;30:3119-31. doi:10.1089/ jmf.2010.0044.

28. International Conference on Harmonisation. Q2(R1) validation of analytical procedures: text and methodology. Geneva, Switzerland: ICH; 2005. http://www.ich.org/fileadmin/Public_Web_Site/ ICH_Products/Guidelines/Quality/Q2_R1/Step4/ Q2_R1_Guideline.pdf. Accessed 15 Jan 2010.

29. International Conference on Harmonisation. QIB stability testing: photostability testing of new drug substances and products. Geneva, Switzerland: ICH; 2005. http://www.ich.org/fileadmin/ Public_Web_Site/ICH_Products/Guidelines/Quality/Q1B/Step4/ Q1B_Guideline.pdf. Accessed 15 Jan 2010.

30. International Conference on Harmonisation. QIA(R2) stability testing of new drug substances and products. Geneva, Switzerland: ICH; 2003. http://www.ich.org/fileadmin/Public_Web_Site/ ICH_Products/Guidelines/Quality/Q1 A_R2/Step4/ Q1A_R2_Guideline.pdf. Accessed 15 Jan 2010.

31. Agência Nacional de Vigilância Sanitária. Resolução RDC n ${ }^{\circ}$, de 29 de julho de 2005. Guia para a Realização de Estudos de Estabilidade. ANVISA; ANVISA Publicações Eletrônicas. 2005.

32. Lustig-Gustafsson C, Kaur JH, Podczeck F, Newton JM. The influence of water content and drug solubility on the formulation of pellets by extrusion and spheronization. Eur J Pharm Sci. 1999;8:147-52. doi:10.1016/S0928-0987(99)00004-4.

33. Rowe RC. Spheronization: a novel pill-making process? Pharm Int. 1985;6:119-23.

34. Kleinebudde P. Shrinking and swelling properties of pellets containing microcrystalline cellulose and low substituted hydroxypropylcellulose: II. Swelling properties. Int J Pharm. 1994;109:221-7. doi:10.1016/0378-5173(94)90384-0.

35. Lautenschlager SMD, Wulf HC, Pittelkow M. Photoprotection. Lancet. 2007;370:528-37. doi:10.1016/S0140-6736(07)60638-2.

36. Ceni GC, Baldissera EM, Antunes OAC, Oliveira JV, Dariva C, Oliveira D. Oxidases from mate tea leaves (Ilex paraguariensis): extraction optimization and stability at low and high temperatures. Bioprocess Biosyst Eng. 2008;31:541-50. doi:10.1007/ s00449-007-0196-y.

37. Fatibello-Filho O, Vieira IC. Analytical use of vegetal tissue and crude extract as enzymatic source. Quim Nova. 2002;25:455-64. doi:10.1590/S0100-40422002000300019.

38. Terefe NS, Yang YH, Knoerzer K, Buckow R, Versteeg C. High pressure and thermal inactivation kinetics of polyphenol oxidase and peroxidase in strawberry puree. Innovative Food Sci Emerg. 2010;11:52-60. doi:10.1016/j.ifset.2009.08.009. 